\title{
THE EFFECTS OF PHYSICAL EXERCISE THROUGH GAME-MODEL AND CIRCUIT-MODEL EXERCISES APPROACH ON THE MAXIMUM AEROBIC CAPACITY
}

(Experimental Study on Students of Faculty of Sports Science Padang State University)

\author{
Umar $^{1}$, Alnedral $^{1}$ \\ ${ }^{1}$ Faculty of Sports Science, Padang State University \\ 1umarmardesia@gmail.com, alnedral@uny.ac.id
}

\begin{abstract}
\section{Objective}

This study was intended to analyze the effect of physical exercise through game-model and circuit model exercises approach on the maximum aerobic capacity
\end{abstract}

\section{Method}

This type of research is quasi-experiments, with treatment in the form of a game model exercise and circuit model exercise. Pre-test of maximum aerobic capacity using the MSFT (Bleep test) instrument was given before treatment. The treatment was given 16 times with details of 3 times per week. Target population is Faculty of Sports Science students of Padang State University, while the affordable population is 30 students of Sport Coaching Education Program academic year of 2013/2014. The sample was selected by using purposive sampling. The data were analyzed by using descriptive and inferential statistics, using t test at significance level $\alpha 0.05$.

\section{Results}

1. The game model exercise gives a significant effect on the increase of maximum aerobic capacity of students of Faculty of Sports Science, Padang State University, $(\rho=0.000<\alpha 0.05)$.

2. The circuit model exercise gives significant effect on the increase of Maximum Aerobic Capacity of students of Faculty of Sports Science, Padang State University, $(\rho=0.000<\alpha 0.05$.)

3. There is a significant difference of effect between the game model exercise and the circuit model exercise to the increase of Maximum Aerobic Capacity students of Faculty of Sports Science, Padang State University, $(\rho=0.001<\alpha 0.05)$.

\section{Conclusion}

Both game model exercise and circuit model exercise have a positive effect on the increase of maximum aerobic capacity. However, the data analysis shows that the circuit model exercise is more effective than game model exercises in increasing maximum aerobic capacity.

Keywords; game model exercises, circuit model exercise, maximum aerobic capacity

\section{Introduction}

Creating athletes full of achievements, requires careful planning, as well as tiered coaching. In the Indonesian Constitution number 3 year 2005, about National Sport System, in Chapter V article 33 paragraph 2 mentioned that; "Sports achievement is a sport that nurtures and develops sportsmanship in a planned, tiered and sustainable manner through training and competition to achieve achievement with the support of science and technology athletics. [10]. Based on the quotation it can be concluded that; to create athletes with achievements the need to perform a planned coaching with the support of science and technology is essential, so that the training process can be maximized in accordance with 
the organs function physiologically. Without involving science and technology in the exercise process, the ability of athletes can't be increased optimally.

One of the coaching programs is through exercises, because the exercise can help athletes improve skills and achievements, especially on four aspects such as; techniques, physical conditions, tactics and strategies, as well as mental ". If one of these aspects is weak, it will affect other aspects, so that athletes can't perform optimally in every game. [3]. One important aspect that an athlete must possess, is the aspect of physical condition which is a fundamental aspect to support another aspects. Elements of physical conditions; strength, speed, endurance, agility, explosive power, balance and coordination. Any elements of physical condition an athlete should possess, it depends on the sport he follows, because each sport has its own characteristics. [1].

On sports such as; medium to long distance run, swimming to 100 meters and up, martial arts, endurance is the main physical components an athlete must have, especially aerobics endurance, because it is needed to be able to perform activities in a relatively long time. Aerobics endurance is the ability of the body to perform activities in a long time without experiencing significant fatigue by using aerobic energy supply.

An aerobic endurance or often called cardio-respiratory endurance is a quality of how the body as a whole supports physical activity and can inhibit the cause of fatigue ". [6]. While Robert Hockey says that; " cardiovascular endurance can be defined as the ability to perform continuous work in performing the tasks of a group of muscles at a relatively long time. [8]. The level of this aerobic endurance will be affected by the level of VO2 max or known as the maximum aerobic capacity. The level of maximum aerobic Capacity is affected by organic components such as; lungs, heart, blood vessels, and blood quality (hemoglobin) and skeletal muscles that will consume oxygen for aerobic energy metabolism processes, resulting in energy for cellular work, including muscle cells [9].

A high maximum aerobic capacity (VO2 max), not only required by athletes when they are exercising or competing, but also needed when they are doing recovery. The defeats often experienced by an athlete in a match, one of which is due to their low maximum aerobic Capacity, this can be seen in every game such as a martial arts [9]. usually, athletes appear prime and violent at the beginning of the round, but in the next round, their tendency decreases, it is evident that they are not supported by maximum aerobic Capacity (VO2max), so the recovery process (recovery) is not running perfectly.

Based on the observations done on students of Faculty of Sports Science in Padang State University, there are still many students who have a low aerobic capacity. This is reflected in each of the following practice classes, as well as doing exercises, many students experienced fatigue faster. The low level of maximum aerobic Capacity of students in Faculty of Sports Science Padang State University, who are being prepared as a coach who will be on duty field in accordance with his profession as a trainer. In addition, the students of Faculty of Sports Science Padang State University are mostly athletes who are still actively participating in various sports events, either sporting the Provincial Sports Week, National Championships (National Championship), National Sports Week (PON), as well as regional championships such as SEA Games, caused by many factors, one of which is the material of the training program provided by the trainer,

\section{Formulation of the problem}

The formulation of the problem is;

1. Can the model of exercise play increase maximum aerobic capacity?

2. Will the circuit training model increase maximum aerobic capacity?

3. Is there any difference in effect between the model of exercise play and the circuit training model on maximum aerobic capacity improvement? 


\section{Research purposes;}

The purpose of this study is to analyze;

1. Effect of play practice model to maximum aerobic capacity,

2. Effect of circuit training model on maximum aerobic capacity,

3. Differences in effect between the model of playing exercises with the model of the exercise of the circuit to the maximum aerobic capacity.

\section{Benefits of research}

The research benefits are as follows;

1. Trainer, as a guide in making physical exercise program,

2. Student / Athlete, as knowledge in performing the right physical exercise,

3. Researchers, increasing the insight of Science and Technology in supporting the profession as educators and trainers.

\section{Methodology}

This type of research is quasi experiment (quasi experiment). Quasi experiment is a type of experimental research in which the researcher can't fully control all variables that may affect the dependent variable. [2]. The research was conducted in the laboratory of the Faculty of Sport Science, Padang State University. The data collection process is done in 2 (two) main stages. The first stage of data collection on the maximum aerobic capacity. The second stage is giving the treatment of exercise model and circuit training model as much as 16 times of practice, ( 3 times per week).

The design of this research is; the two groups pretest and posttest design. Population in this research, is student of Faculty of Sport Science Padang State University as target population (target population). While the affordable population (affordable population) is a student Faculty of Sport Science Padang State Sport Education program class of 2013/2014 registered in the semester of July December 2013/2014. While the sample used in this study are 30 students with a purposive sampling technique.

The research instrument for measuring the maximum aerobic capacity is Bleep test (MSFT). Data analysis using t test with significance level $\alpha=0.05$.

\section{Research result}

\section{A. Data Description}

\section{Initial Data Maximum Aerobic Capacity Group of Play Training Methods}

Based on the results of descriptive data analysis of 15 people group exercise training method, obtained the highest score 47.1, lowest score 30.6, average score 37.7, span 16.5. For more details can be seen in the following table:

Table 1. Initial Data Maximum Aerobic Capacity Group of Play Training Methods

\begin{tabular}{|c|c|c|c|}
\hline No & Interval class & (Fa) & (Fr) \\
\hline 1 & $30.6-33.4$ & 4 & 27 \\
\hline 2 & $33.5-35.7$ & 2 & 13 \\
\hline 3 & $35.8-38.5$ & 2 & 27 \\
\hline 4 & $38.6-41.2$ & 4 & 20 \\
\hline 5 & $41.3-47.5$ & 3 & $100 \%$ \\
\hline
\end{tabular}




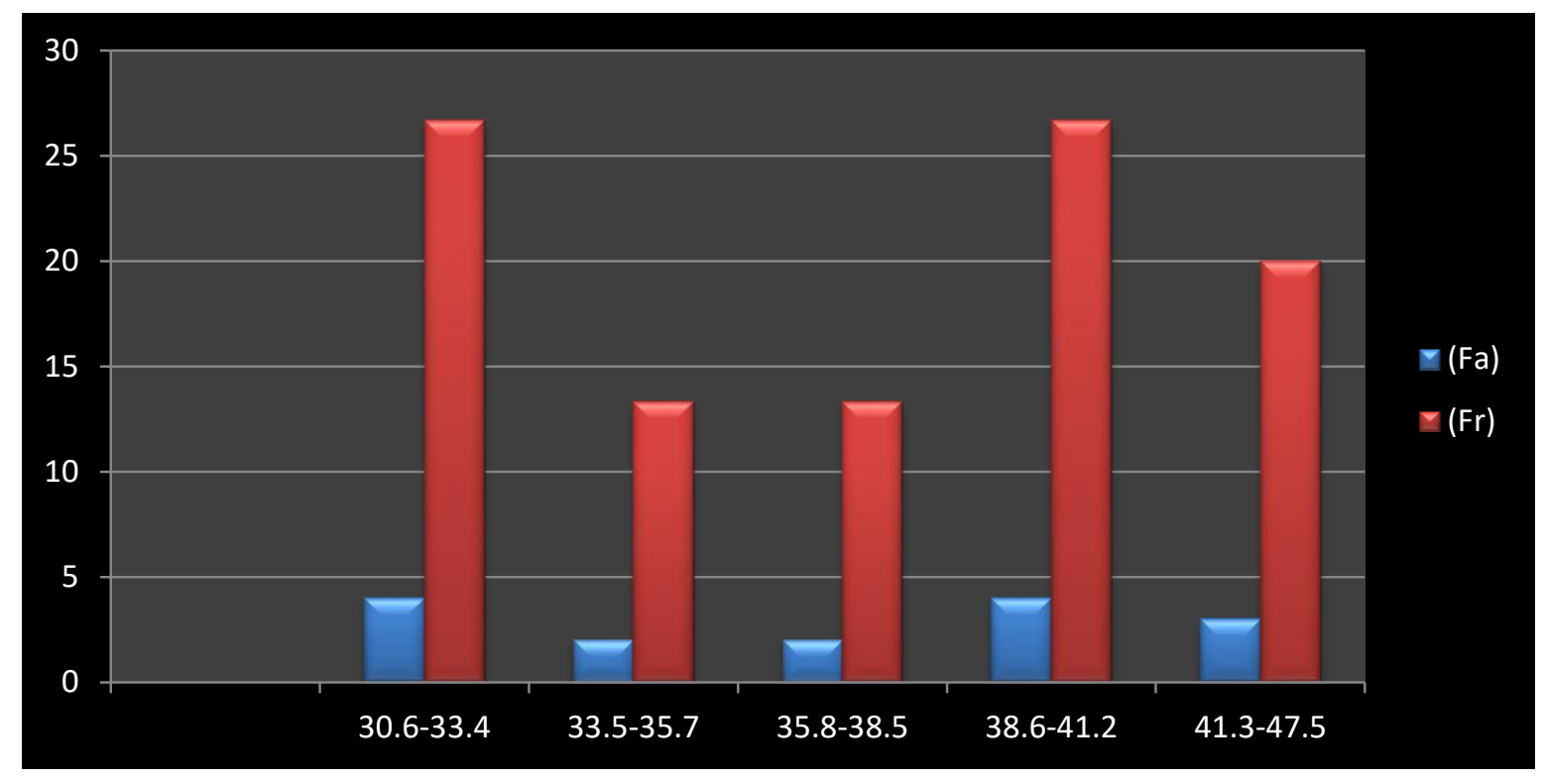

Fig. 1. Histogram frequency score Maximum Aerobic Capacity group of Play Training Methods

\section{Initial Data Maximum Aerobic Capacity Group of Circuit Training Methods}

Based on the results of descriptive data analysis of 15 people group of exercise training methods, obtained the highest score 46.8, lowest score 30.6, average score 37.7, range 16.2 and standard deviation 5.03. For more details can be seen in the following table:

Table 2. Initial Data Maximum Aerobic Capacity Group of Circuit Training Methods

\begin{tabular}{|c|c|c|c|}
\hline No & Interval Class & (Fa) & (Fr) \\
\hline 1 & $30.6-33.4$ & 3 & 20 \\
\hline 2 & $33.5-35.7$ & 4 & 27 \\
\hline 3 & $35.8-39.5$ & 2 & 13 \\
\hline 4 & $39.6-41.2$ & 3 & 20 \\
\hline 5 & $41.3-46.8$ & 3 & $100 \%$ \\
\hline
\end{tabular}




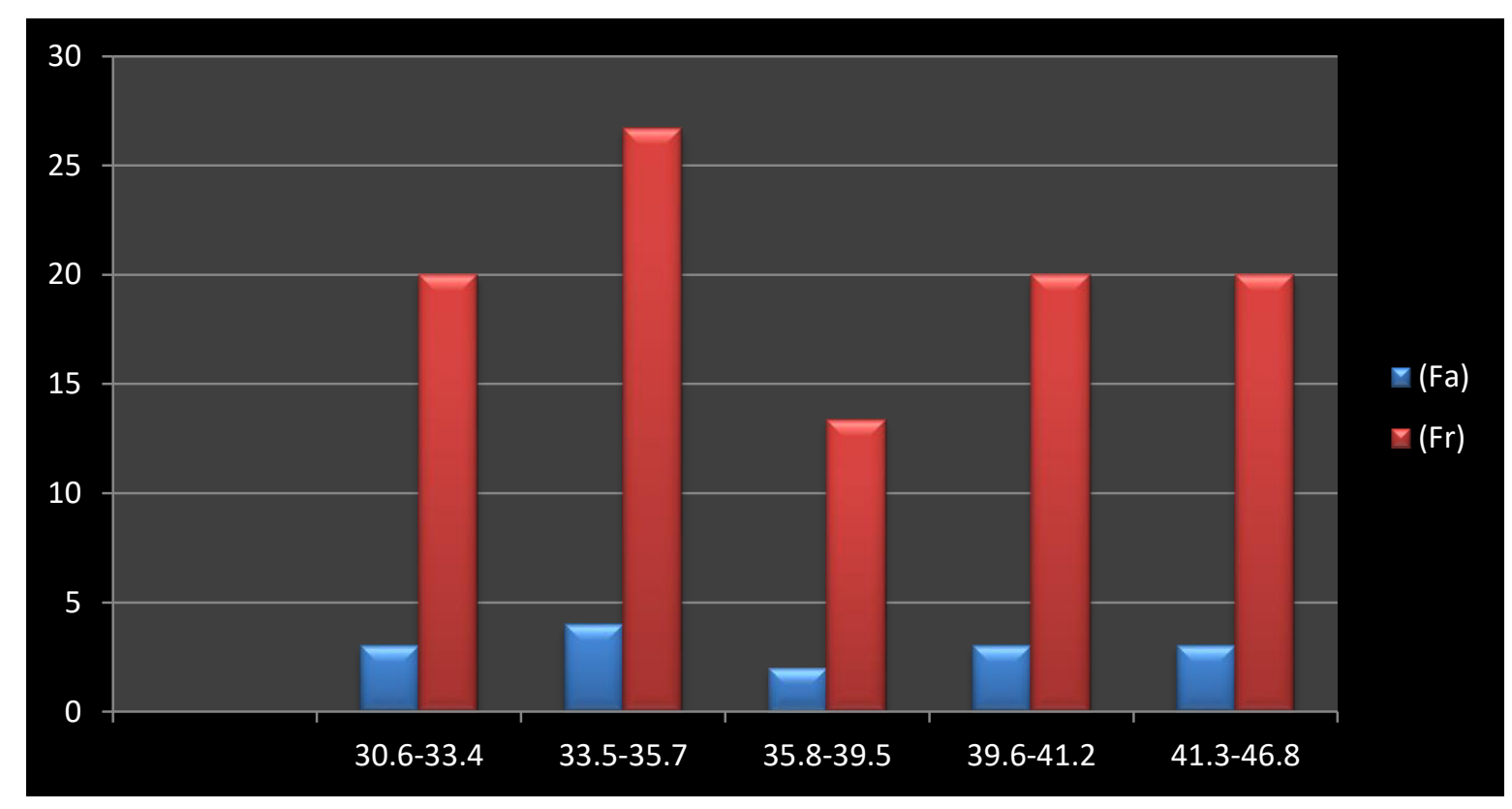

Fig. 2. Histogram frequency score Maximum Aerobic Capacity group of Play Training Methods

\section{Final Data Maximum Aerobic Capacity Group of Play Training Methods}

Based on the results of descriptive data analysis of 15 people group of exercise training methods, obtained the highest score 48.4 , the lowest score 32.5 , the average score of 38.8 , range 15.9 and standard deviation 4.67. For more details can be seen in the following table:

Table 3. Final Data Maximum Aerobic Capacity Group of Play Training Methods

\begin{tabular}{|c|c|c|c|}
\hline No & Interval Class & (Fa) & (Fr) \\
\hline 1 & $32.9-35.6$ & 4 & 27 \\
\hline 2 & $35.7-38.4$ & 2 & 20 \\
\hline 3 & $38.5-40.3$ & 3 & 20 \\
\hline 4 & $40.4-42.7$ & 3 & 20 \\
\hline 5 & $42.8-48.5$ & 3 & $100 \%$ \\
\hline & Total & 15 & \\
\hline
\end{tabular}




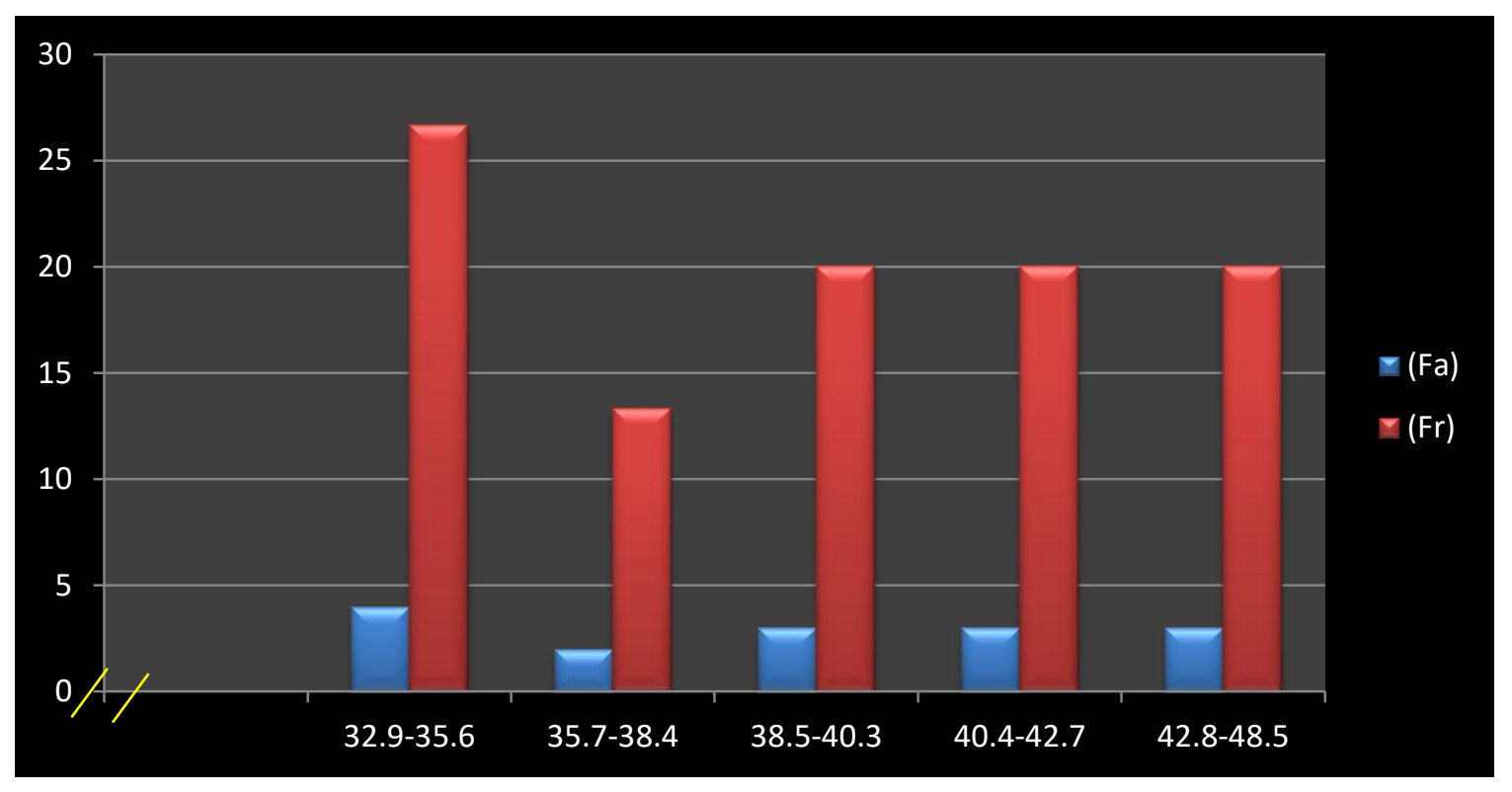

Fig. 3. Histogram frequency score Maximum Aerobic Capacity group of Play Training Methods

\section{Final Data Maximum Aerobic Capacity Group of Circuit Training Methods}

Based on the results of descriptive data analysis of 15 people group exercise circuit method, obtained the highest score 49.0, the lowest score 34.3, the average score 40.6, range 14.7 and standard deviation 4.56. For more details can be seen in the following table:

Table 4. Final Data Maximum Aerobic Capacity Group Circuit Exercise Method

\begin{tabular}{|c|c|c|c|}
\hline No & Interval Class & (Fa) & (Fr) \\
\hline 1 & $34.3-35.8$ & 3 & 20 \\
\hline 2 & $35.9-37.6$ & 1 & 7 \\
\hline 3 & $37.7-40.4$ & 3 & 20 \\
\hline 4 & $40.5-42.7$ & 3 & 20 \\
\hline 5 & $42.8-50.00$ & 5 & 33 \\
\hline & Total & 15 & $100 \%$ \\
\hline
\end{tabular}




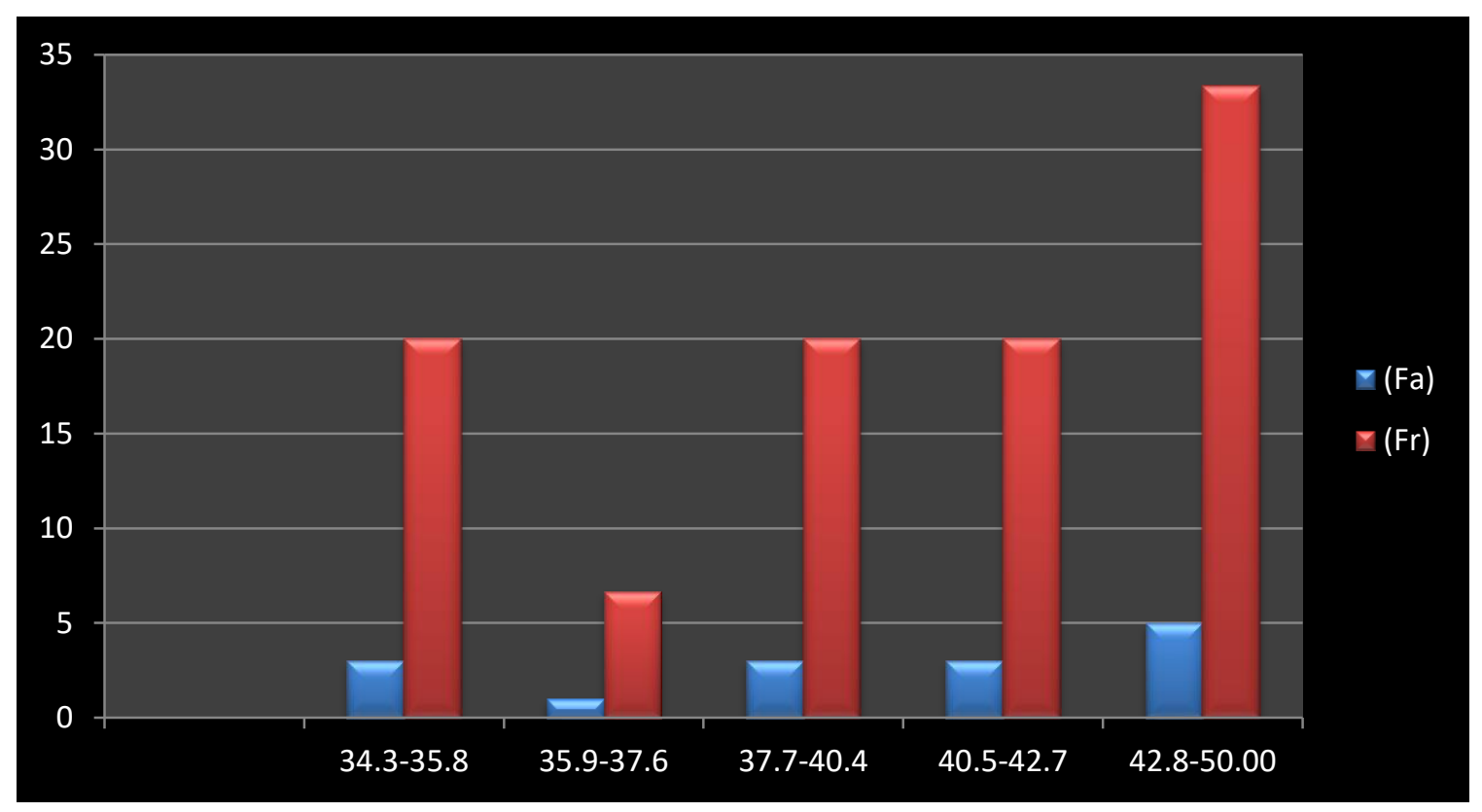

Fig. 4. Histogram frequency score Maximum Aerobic Capacity group of Play Training Methods

\section{B. Hypothesis Testing}

\section{First Hypothesis}

The hypothesis proposed in this study is "There is an effect of the exercise model of play on the maximum aerobic Capacity. Based on result of data analysis turns out $\rho=0.000<\alpha=0.05$. Thus it can be concluded that there is effect of the method of playing exercises on aerobic athlete's maximum aerobic capacity. For more details can be seen in the following table;

Table 5. Test Result T Test Data Pretest and Posttest Play Group

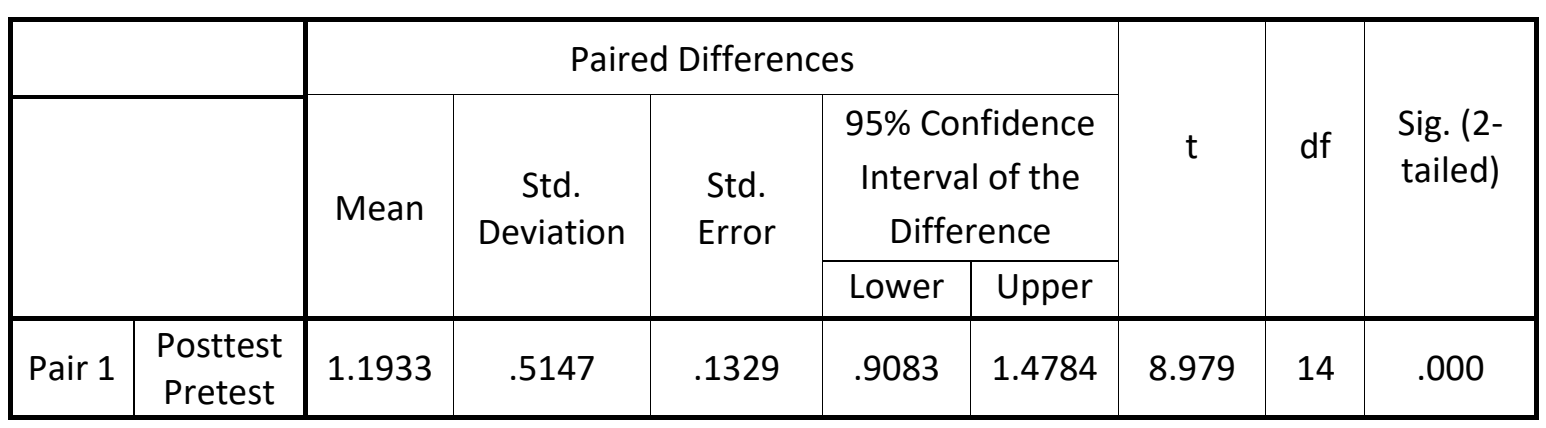

Thus the hypothesis proposed in this study that says there is effect of the method of playing exercises on aerobic Capacity of athletes is acceptable.

\section{Second Hypothesis}

The hypothesis proposed in this study is "There is effect of Circuit training model to the maximum aerobic capacity. Based on result of data analysis turns out $\rho=0.000<\alpha 0.05$. Thus it can be concluded that there is effect of circuit training method on aerobic Capacity of athlete. For more details can be seen in the following table; 
Table 6. Test Result Analysis of Data Pretest and Posttest of Circuit Group

\begin{tabular}{|c|c|c|c|c|c|c|c|c|c|}
\hline & \multicolumn{5}{|c|}{ Paired Differences } & \multirow{3}{*}{$\mathrm{t}$} & \multirow{3}{*}{$\mathrm{df}$} & \multirow{3}{*}{$\begin{array}{l}\text { Sig. (2- } \\
\text { tailed) }\end{array}$} \\
\hline & & \multirow[t]{2}{*}{ Mean } & \multirow[t]{2}{*}{$\begin{array}{c}\text { Std. } \\
\text { Deviation }\end{array}$} & \multirow[t]{2}{*}{$\begin{array}{l}\text { Std. } \\
\text { Error }\end{array}$} & \multicolumn{2}{|c|}{$\begin{array}{c}95 \% \text { Confidence } \\
\text { Interval of the } \\
\text { Difference }\end{array}$} & & & \\
\hline & & & & & Lower & Upper & & & \\
\hline Pair 1 & $\begin{array}{c}\text { Posttest } \\
\text { Pretest }\end{array}$ & 2.9000 & .7521 & .1942 & 2.4835 & 3.3165 & 14.933 & 14 & .000 \\
\hline
\end{tabular}

Thus the hypothesis proposed in this study that says there is effect of the method of circuit training on maximum aerobic capacity of athlete is acceptable.

\section{Third Hypothesis}

The hypothesis proposed in this study is "There is a difference in the effect between the model of playing practice and the circuit training model on the aerobic capacity of the mask. Based on result of data analysis turns out $\rho=0.001<\alpha 0.05$. Thus it can be concluded that there is a difference of effect between the method of playing exercises and the method of circuit training on aerobic athlete's capacity. For more details can be seen in the following table;

Table 7. Result of t Test Analysis Posttest Data between Play Group and Circuit Group

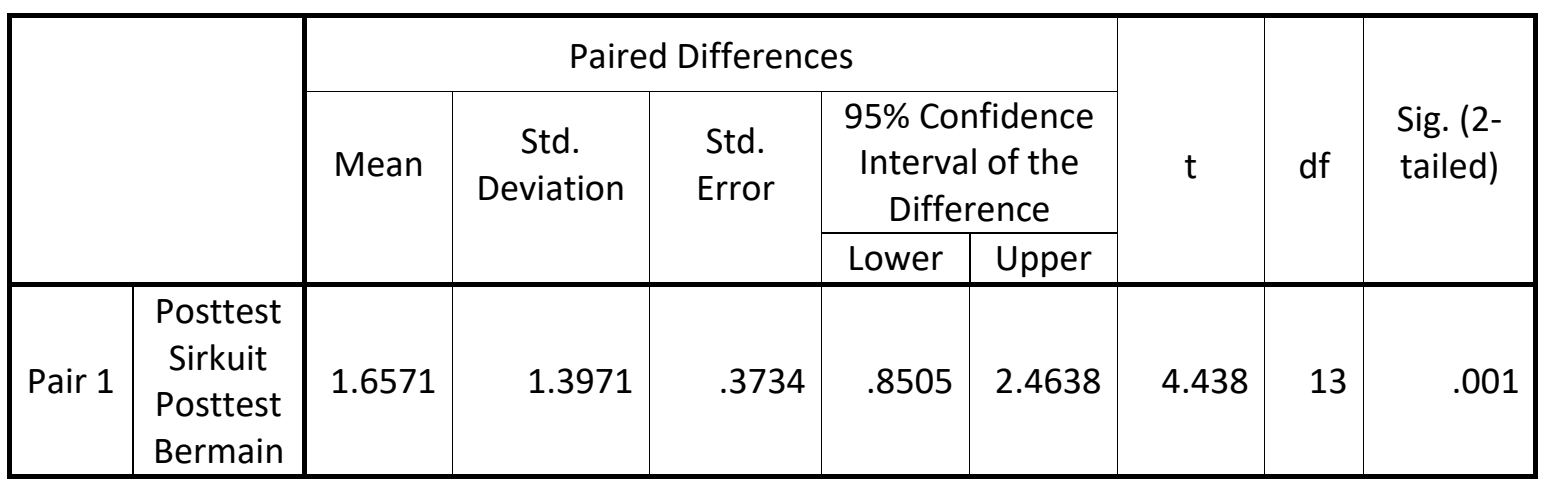

Thus the hypothesis proposed in this study that says there is a difference in the effect between the method of play practice and the method of circuit training on aerobic aerobic Capacity of athlete is acceptable, and if seen from the difference of mean score, then the circuit training model is more effective to increase maximum aerobic Capacity.

\section{Discussion}

\section{Effect of Model of Playing Exercise to Maximum Aerobic Capacity}

The result of data analysis done in this research turns out $\rho=0.000<\alpha 0.05$. That is, the model of playing practice can increase the maximum aerobic capacity significantly. Increased maximum aerobic capacity as a result of the exercise, possibly caused by several factors as follows; 
First, the intensity of exercise averages $70 \%-80 \%$ of the maximum pulse rate. The intensity has already entered the training zone to increase maximum aerobic capacity (VO2 max). This is as it is said by; Matt Fitzgerald that; Research suggests that vigorous-intensity exercise $(60-84 \%$ oxygen consumption reserve $\left.\left(\mathrm{V}^{\circ} \mathrm{O} 2 \mathrm{R}\right)\right)$ results in greater increases in aerobic capacity than moderateintensity exercise (40-59\% V'O2R). [6].

Research shows that a strong / high intensity exercise $(60-84 \%$ of reserve oxygen consumption ( $\left.\mathrm{V}^{\circ} \mathrm{O} 2 \mathrm{R}\right)$ ) results in greater increases in aerobic capacity than moderate exercise intensity (40-59\% V'O2R). This is reinforced by O'Connor, (2009) that the effects of exercise exercises to increase maximum aerobic capacity (VO2 max) can already occur at $70 \%$ exercise intensity. For more details can be seen in table 4 .

Tabel 8. Zona intensitas latihan untuk meningkatkan VO2 Max, [4].

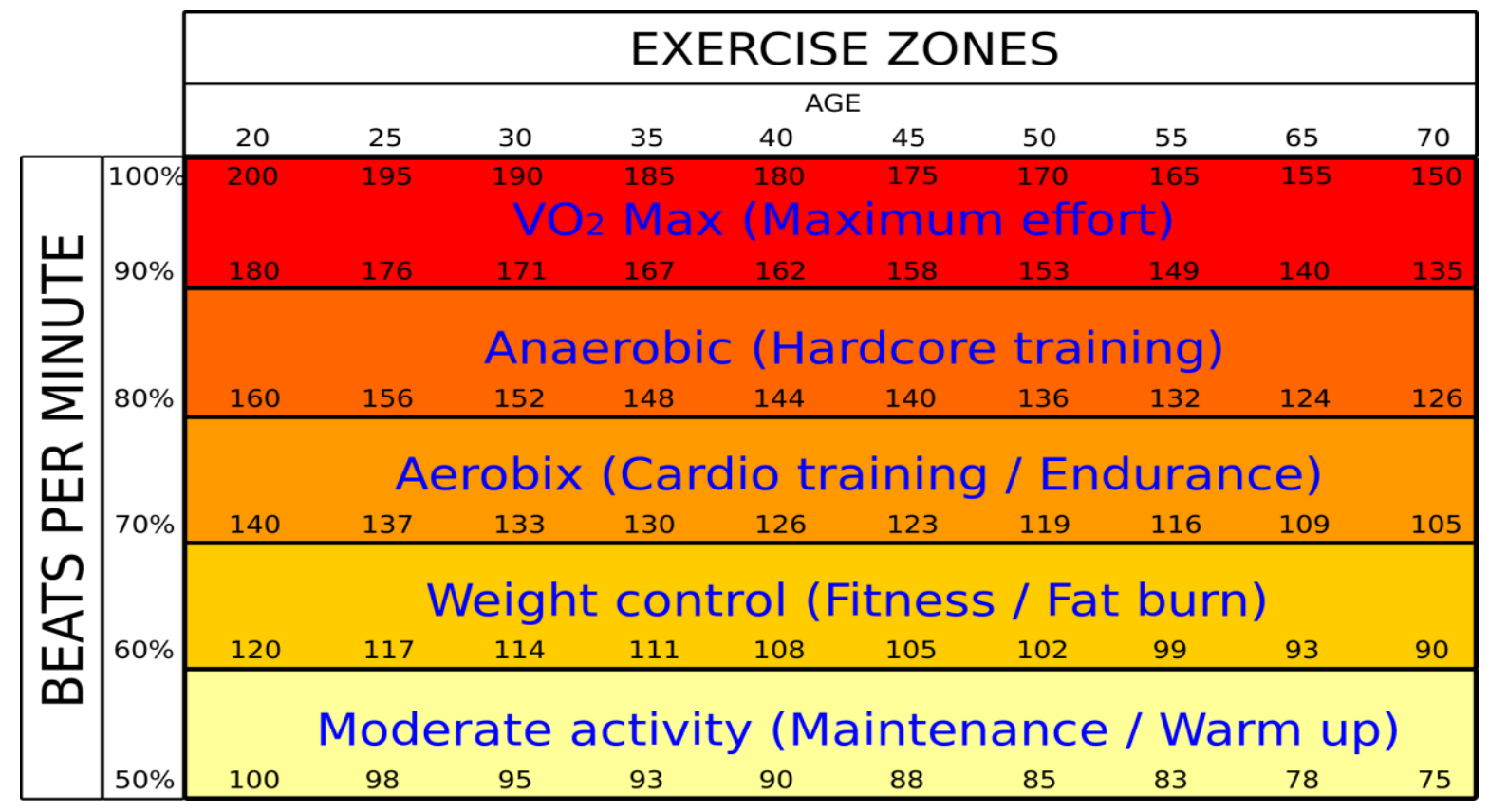

Based on the quote and table 4, it can be concluded that the increased aerobic capacity is maximum as the effect of the training method of play. First, because the intensity of the exercise through pulse measurements achieved in each training session averaged $70 \%-80 \%$ of the maximum pulse. Secondly, the samples in the exercise of this play method are full of vigor, excitement and high motivation. Because this method of play has considerable motion variations that will involve most of the muscles of the body, so the cardiovascular system is maximized, without experiencing significant fatigue from each sample.

\section{Effect of Circuit Exercise Model on Maximum Aerobic Capacity}

The result of data analysis done in this research turns out $\rho=0.000<\alpha 0.05$. That is, the circuit training model can increase the maximum aerobic capacity significantly. Increased maximum aerobic capacity as a result of the exercise, possibly caused by several factors as follows; First, As with the method of exercise, the intensity of the exercise achieved during the exercise is $70 \%-80 \%$ of the maximum pulse rate. The intensity has already entered the training zone to increase maximum aerobic capacity (VO2 max). Second, circuit training will train most of the 
muscles of the body, because each station (station) contains different or varied forms of exercise. Third, the exercise circuit model in the implementation of each post is more focused on certain muscles, so the effect of exercise on the muscles involved in each form of exercise can be more leverage.

\section{Differences in effect between the model of exercise play and the circuit training model of the Maximum Aerobic Capacity}

Based on the results of data analysis performed in this study was $\rho=0.001<\alpha 0.05$. That is, there is a difference of effect between the model of exercise play with circuit training model to increase the maximum aerobic capacity. These differences indicate that the model of the cyclical exercise is more effective than the exercise-training model to increase maximum aerobic capacity. This is based on the average score of the circuit training model 40.6 is greater than the average score of the exercise-training model is 38.8. The difference in the effect of this exercise may be due to several factors as follows;

First, the circuit training model focuses more on certain muscles only according to the shape of the movements performed in each post, so that the exercise effect is also more focused. Second, the training program such as intensity, repetition, set, duration and well controlled recovery, so that the effects of exercise can be more leverage.

\section{Conclusion}

Based on some of the things described above, it can be concluded that;

1. The model of playing exercises can increase the maximum aerobic capacity, as evidenced by the results of t-test $=0.000<\alpha 0.05$.

2. Circuit training model can increase maximum aerobic capacity, this is proved by the result of $\mathrm{t}$ test $=$ $0.000<\alpha 0.05$.

3. There is a difference between the exercise model and the circuit training model for maximum aerobic capacity improvement, as evidenced by the result of t-test $=0.001<\alpha 0.05$.

\section{Suggestion}

1. To increase maximum aerobic capacity of athlete, can be used both kinds of model of this exercise,

2. To get maximum aerobic capacity increase as expected, it is better to use more varied training methods.

\section{Referensi}

Bompa, Haff., G.G., 2009. Periodization Theory and Methodology of Training. Fifth ed. Champaign: Human Kinetics.

Donald Ary., Luchy C.Jacobs dan Asghar R., 2004. Pengantar Penelitian dalam Pendidikan. Yogyakarta: Pustaka Pelajar offset.

Harsono., 1996. Prinsip dan Metodologi Pelatihan, Jakarta: PIO-KONI Pusat,

http://hobilari.com/2014/06/04/maximum-and-target-heart-rate/

Johny Lycholat., 1989. Circutit Weight Training. Northamptonshire: Thorsons Publishing Group. 
Matt Fitzgerald. 2005. How to Maximize Your VO2max Training. http://www. active.com/running/articles/how-to-maximize-your-vo2max-training

O'Connor, Lanty., 2009. Interval Training: Increase your VO2max, lactate threshold, stroke volume, and improve your cholesterol, http: //workouthacker .com/2009/10/interval-training-increaseyour-vo2max.

Robert Hockey., 1981. Physical Fitness. St. Missouri: CV. Mosby Company.

Umar., 2014. Fisiologi Olahraga. Padang: UNP Press.

UU RI No. 3 tahun 2005., 2006. Sistem Keolahragaan Nasional. Jakarta: Kemenpora. 